\title{
Marine ecosystem testing units: Design for assessment of benthic organism responses to low-level pollutants
}

\author{
W. P. Davis, B. S. Hester, R. L. Yoakum \& R. G. Domey \\ Bears Bluff Field Station, Gulf Breeze Environmental Research Laboratory, \\ U.S. Environmental Protection Agency; \\ Jobns Island, South Carolina, USA
}

\begin{abstract}
Marine Ecosystem Testing Units" (METU) is an experimental design for integrating responses of communities of marine organisms to low level pollutants under natural conditions of temperature, weather, season, precipitation, sunlight, etc. Ninety-six testing units are arranged in a regimen for pollutant exposure and systematic sampling. Organisms harvested are sorted and enumerated first to major taxa, subsequently to species level. Data are subjected to multi-variate statistical analysis to elucidate relative effects of pollutant, duration of test (harvest), season, and type of organism. Sampling is replicated in time and space. The first year of operation has demonstrated distinct responses to chlorination at levels below chemical detectability.
\end{abstract}

\section{INTRODUCTION}

Among bioassays, experiments with mixed species communities in marine ecosystems have inherently more design challenges and analytical problems than the more typical toxicity dose-response bioassays. Interaction of such factors as physical/ chemical processes, growth, reproduction and behavioral events yielding requirement for multi-variance analyses; these are a few of the features automatically incorporated into the experimental system. Perhaps then, only the foolhardy become involved in "ecosystem" experiments. For whatever reasons, the literature contains very little documentation of experimental designs which bridge the wide gap between toxicity-effects research in the typical laboratory context with field ecological or ecosystem investigations of low level, long-term pollution effects.

Marine ecosystem test units, hereafter referred to as METU, were designed and constructed with these factors in mind: (1) Design testable ecosystem units to be run exposed to cycles of natural factors (seasonal, weather, biological, tidal). (2) Insure that natural associations or communities develop which represent a recognizable "ecotome" or "biome". (3) By variance analyses determine if communities or associations reflect natural variance, and experimental manipulations, as well. (4) De- 
termine if response parameters to experimental manipulations yield useful insight to responses to stresses or pollutants in nature. (5) Determine if the design yields ecologically significant results as well as being economically manageable. That is to say, can a scientifically valid system be designed to be realistic in economical terms of personnel, equipment resources, and produce timely out-put of observations and results?

Under these criteria, METU has performed more or less positively, but it must be further examined and tested under other conditions before any universality in application can be recommended. METU does provide a conceptual and actual model system for certain types of marine environmental experimentation.

\section{DESIGN OF MARINE ECOSYSTEM TESTING UNIT EXPERIMENT}

The basic layout of METU consists of 96 rectangular containers of 37.51 capacity. The arrangement of twelve tables, the seawater supply and drainage is illustrated in Figure 1. Seawater is pumped from the tidal estuary of the North Edisto River (South Carolina, USA) whose salinity ranges 21-29\% over the year. Water is pumped from $1 / 2 \mathrm{~m}$ below the river surface at a rate of about 400 gals $\min ^{-1}$ to a large head tank, thence to a secondary head tank, then to distributors, which break delivery in the pattern illustrated in Figure 1. The water is unfiltered

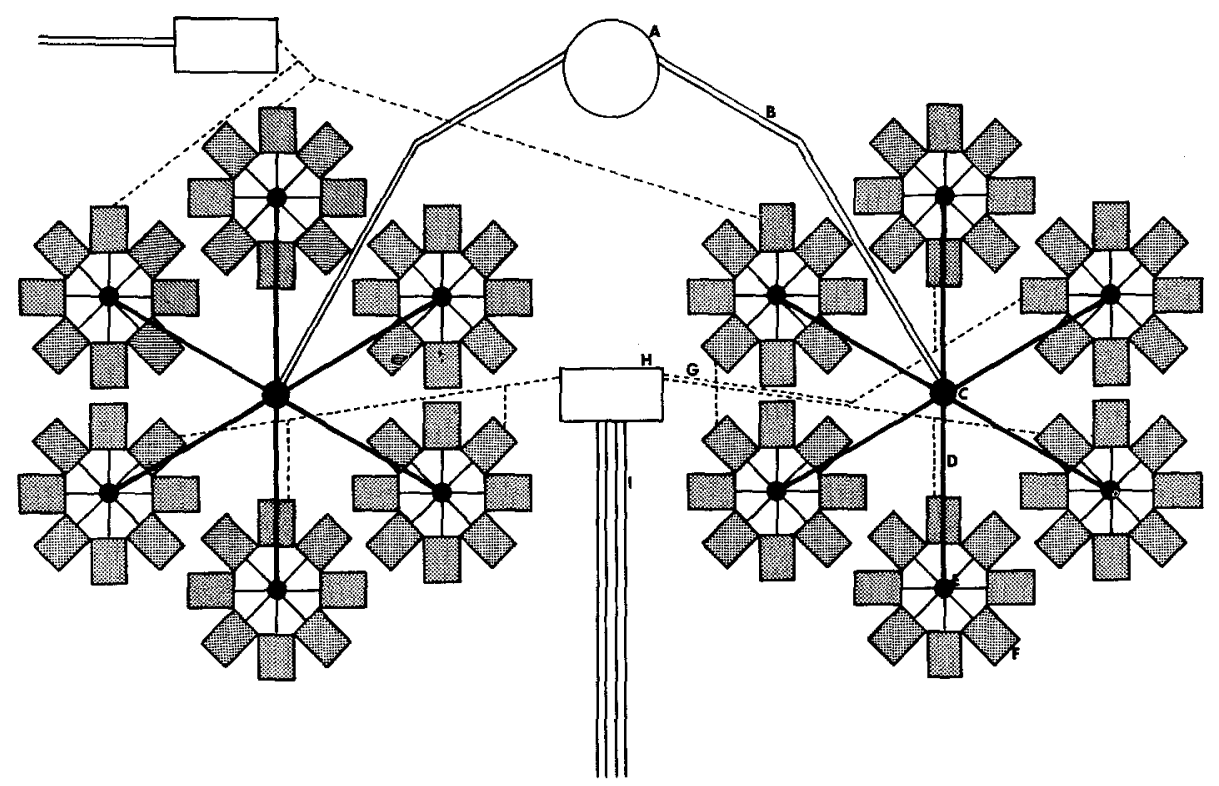

Fig. 1: Schematic of "Marine Ecosystem Testing Unit" (METU) arrangement. A METU Head tank/water tower. $B$ Seawater supply line to secondary head container. $C$ Secondary head/ distributor. $D$ Seawater supply line to test container platforms. $E$ Distributor/mixing chambers. $F 37.51$ marine community test container. $G$ Drain lines from test platforms. $H$ Sump stations. $I$ Delivery lines to effluent ponds 
(other than passing through $1.6 \mathrm{~mm}$ fiberglass screening) carrying with it nutrients, suspended particles and entrained plankton, and larval organisms. The water flows at a constant rate from intake at the pump to its destination about $30 \mathrm{sec}$ later at the METU units. Communities formed in the test units are therefore continuous, synoptic, and incorporate behavioral substrate preferences of the entrained larvae. The suitability of the test container itself to the needs of the organisms is therefore

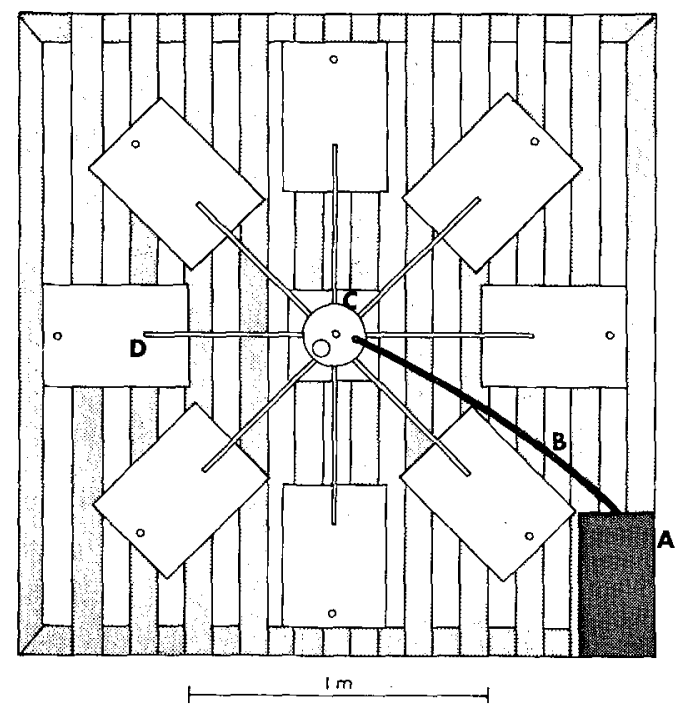

Fig. 2: Arrangement of 37.51 containers on each dosing platform. A Metering pump for test substance. $B$ Delivery line from pump to seawater mixing distributor. C Distributor/mixing chamber delivering water to test containers. $D 37.51$ test containers for marine community development
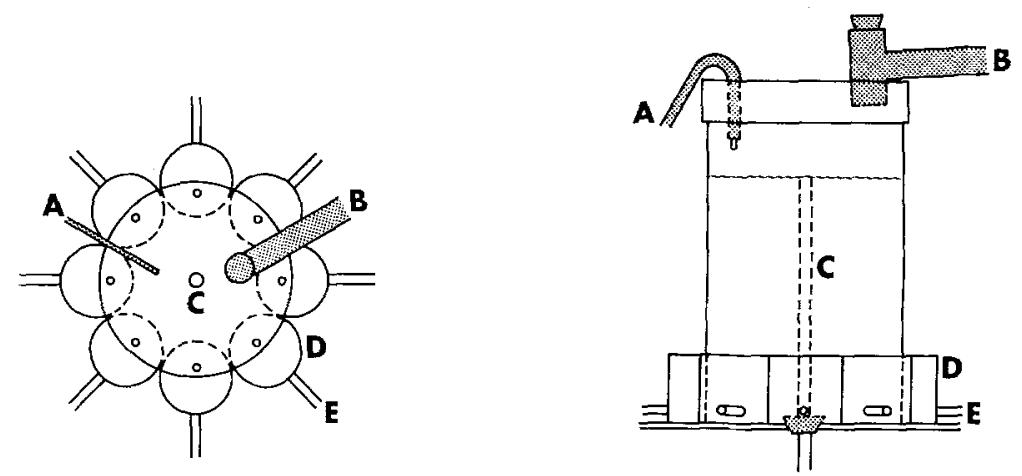

Fig. 3: Lateral (right) and overhead (left) views of the seawater mixing distributor for each platform of eight testing containers. $A$ Input line from metering pump. $B$ Seawater delivery line from secondary head container. $C$ Stand-pipe leveling drain to maintain constant head level. $D$ Cups receiving water from the mixing chambers (small circles represent orifices of drain). E Delivery line to 37.5 liter testing container 
ultimately reflected in the communities that develop there. Water flows to each test container at the rate of $40 \mathrm{l} / \mathrm{h}$ (Figs 2,3,4). Test containers (units) are arranged in rosettes of eight (Figs 2,3) on 12 tables to achieve bisymmetrical and controlled distribution of the flowing seawater. Water leaves test units to collector pipes, then to sumps where it is pumped to effluent ponds for further study of potential longrange effects of treatment versus non-treatment.

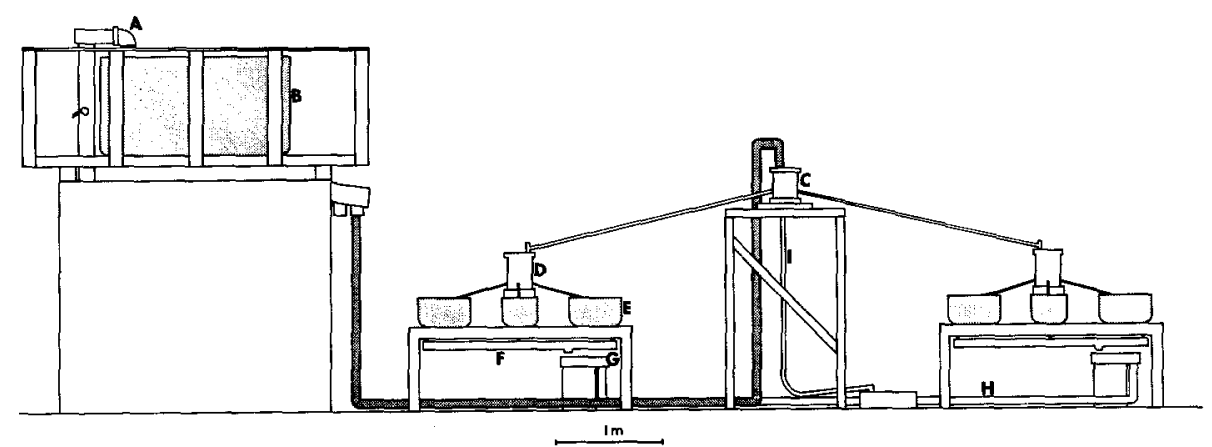

Fig. 4: Lateral view of water flow pattern through METU. $A$ Seawater inflow pipe. $B$ METU head tank/water tower. $C$ Secondary head container distributing to platforms. $D$ Distributor mixing chambers. $E 37.51$ community test containers. $F$ Platform collector drain pipes. $G$ Containers for monitoring experimental effluents. $H$ Drain line to sump. $I$ Water level stand pipe drain

The following summarizes physical-chemical parameters, and the frequency of sampling (Erickson \& Foulk, in press): temperature in air and container water (daily), salinity (daily), $\mathrm{NH}_{3}$ (seasonally), ATP (weekly), $\mathrm{O}_{2}$ (seasonally), $\mathrm{Cl}$ (weekly, sediment (sampling regime), $\mathrm{pH}$ (daily, now biweekly).

The present question under investigation using this ecosystem experimental design is: Will naturally occurring communities of estuarine organisms respond to subdetectable levels of chlorination? In the United States over 200,000 tons of chlorine are applied each year in disinfection processes by industry, municipal sewage treatment plants, and as a biocide in pass-through cooling waters during electric power generation. Dosage rates of chlorination in industrial applications are normally based on maintaining some prescribed "chlorine residual" in an effluent flow. Since chlorine rapidly transforms or degrades through oxidation processes (Davis \& Middaugh, 1976; Jolley, 1976), waters with higher biological activity typically receive greater dosage levels. This can result in preposterous levels of chlorination simply to get a chemically detectable "residual oxidant level" indicated on an amperometric titrator. This detection instrument is nearly the universal tool used to measure chlorination levels. Recent findings from chemical studies of chlorination in marine waters have reinforced the fact that bromine is released (Dove, 1970; Carpenter \& Macalady, 1976). Additionally, the titrator only responds to active oxidative states of compounds at the moment of sampling. Chemical processes are dynamic, especially those involving chlorine, and a cascade of processes and compounds are 
occurring, many highly significant, and outside the amperometric titrator's range of sensitivity (Macalady et al., in press).

With these factors in mind we desired to see if and how organisms responded, in waters with a high "chlorine demand" at chlorination levels below chemical sensitivity of the amperometric titrator.

Solutions of $5 \%$ laboratory grade sodium hypochlorite are metered into "satellite" water distribution towers by syringe pumps set to deliver $37 \mathrm{ml}(25 \mathrm{ppm}$ Cl) over $24 \mathrm{~h}$ (Figs 2, 3). By assigning different numbers of syringes, 3 levels of $\mathrm{NaOCl}$ (each level - 24 tanks) were continually dosed as follows: Lo (control), $\mathrm{L}_{1}(0.125 \mathrm{ppm}), \mathrm{L}_{2}(0.250 \mathrm{ppm})$, and La $(0.5 \mathrm{ppm})$.

These dosage levels were previously determined to be "sublethal" (in the acute toxicological sense) and were not chemically detectable, except as "trace" on coldest $\left(5^{\circ} \mathrm{C}\right)$ days of the year.

\section{BIOLOGICAL SAMPLING}

The experimental design utilizes three "harvest" periods of 30,60 , and 120 day intervals. These frequencies provide monthly, bimonthly and seasonal periods for community evaluations. Each 120 days all tanks are rerandomized in terms of harvesting frequency assignment. The configuration of tanks for each harvest period is: 8 tanks - level 0, 8 tanks - level 1, 8 tanks - level 2, 8 tanks - level 3 .

Procedural steps for a typical harvest are briefly summarized: (1) Removal of macroalgae and preservation in $5 \%$ seawater formalin. (2) Siphon tank contents through $1 \mathrm{~mm}$ and $0.5 \mathrm{~mm}$ nytex monofilament sieves. Entire contents of tank are sieved including sediment, water, remaining algae and scrapings from tank sides. (3) Preservation of sievings and cataloging for sorting and identification (fixation in $8-10 \%$ seawater formalin). (4) Settling and storage of sediments for geological evaluation.

\section{SORTING AND ENUMERATION}

Teams of technicians and aides sort and enumerate sampled organisms into major taxa. Each harvest sample is split into equal portions and sorters work on a single sample simultaneously. Organisms are transferred from formalin to $70 \%$ ethanol; detritus is set aside. Subgroups of major taxa (e.g. amphipods) are prepared for further examination and species identification by taxonomic experts for the respective group.

Sorted organisms are enumerated by major taxon for preliminary statistical analysis. As identifications proceed to the species levels, statistical analyses are rerun.

At this time, one year's sampling is sorted to major taxa (in most cases to the generic level). Figure 5 gives a summary of major taxa sampled from 60-day communities. Frequency of each invertebrate group is ranked by per cent of occurance in a dosage level by harvest period; " $n$ " represents the pooled denominator for

8 tanks at one exposure level. Before these were pooled a factorial analysis of 
variance is run to ascertain good agreement among replicates and tables. For example, for April 1976 F-ratios for "tables" were 0.54, and for replicates were 0.006 , so variance was considered insignificant and normal.

In this paper we focus upon the experimental design and first year's pattern of organism abundance rather than analytical conclusions. However, it is significant that qualitatively, macroalgae which have not here been quantified, clearly responded to chlorination levels; whereas the reaction of invertebrates to dosage levels at the major taxon level is not so clearly demonstrated. It should be kept in mind, however, that interaction of physical factors, chlorination, and resulting community structure is strongly implied.

\section{STRATEGY OF STATISTICAL ANALYSIS}

This experimental project is essentially a multivariate problem in which the variables are (1) levels of toxic substances. induced by chlorinating seawater (2) variations of exposure time to the polluted seawater by 30,60, and 120 (data not summarized) day intervals (3) all seasons (4) two annual cycles totaling 720 days in all (5) all taxa in a (6) replicated experimental design. The numbers of major taxa are noted as well as frequencies for each taxon by major classification and species. These data will be evaluated according to a number of statistical methods. The more inclusive techniques are favored. For example, these data invite detailed experimental examination by various sorts of diversity measures among which is a relatively new bias-free system devised by Smith \& Grassle (1977). This technique has several advantages, among which is its freedom from the influences of extreme frequencies either very large or very small of one or more organisms in a given ser (as amphipods versus barnacles: Fig. 5a, 1-Jul./Sep.). Equally advantageous in its unbiased characteristics is the fact that variances can be estimated for every taxon in the set. Measures of equitability are to be included although these mathematical forms are not as well developed as are measures of diversity. These data, multivariate in nature, appear to be amenable to higher, more complex, levels of integrated evaluation by 4 and 5 -way analyses of variances. This technique allows evaluation of the relatively independent influence of the main variables listed above as well as their higher order combinations. Evaluation of replicates allows inferring the reliability of the outcome and identifying possible synergistic effects if any, as indicated by significant interaction of variables. Preliminary analyses of variance studies of the partial data suggest the powerful influences of seasonal variation and the presence of interaction effects among variables for those taxa with frequencies sufficient for application with this technique. Replicates show no significant difference which indicates the high overall reliability of the METU system. Special Note: Condition of replication was randomly paired tanks. In effect, this means that the experiment was duplicated both in space and time. There was no significant difference among the replicates for the paired experiment.

Nothing more should be said about advance analyses until the data are complete. Of course, other statistical options are available and probably will be practical 


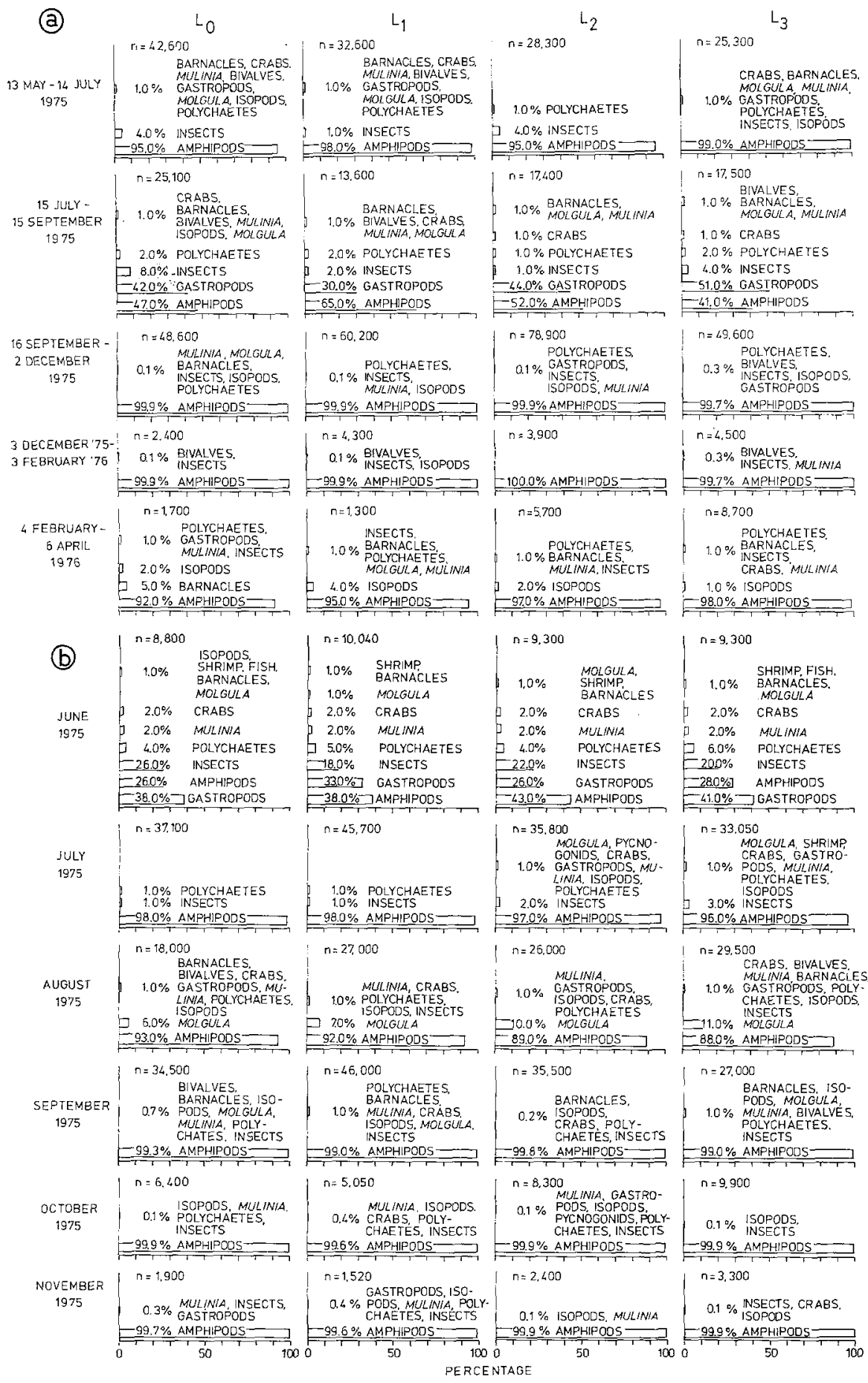

Fig. 5: Distribution of organisms; (a) 60-day duration exposure; (b) 30-day duration exposure; $\mathrm{L}_{0}=$ control; $\mathrm{L}_{1}=0.125 \mathrm{ppm} \mathrm{NaOCl} ; \mathrm{L}_{2}=0.25 \mathrm{ppm} \mathrm{NaOCl} ; \mathrm{L}_{3}=0.5 \mathrm{ppm} \mathrm{NaOCl} ; \mathrm{n}=$ number of organisms examined 
here, i.e. factor analysis, cluster analysis, multiple correlation, regression, and so on (Livingston, 1974).

\section{DISCUSSION OF FIRST YEAR (1975-1976) RESUL'TS}

In addition to establishing and executing the methodology of operating METU, we have been successful in catching up with preliminary sorting and enumeration. Figure 5 lists by sample and chlorination dosage level, the principal organisms (excepting algae) comprising the communities in METU testing containers. $\mathrm{n}$ in each case represents the number of all organisms (excepting algae) enumerated for eight test units. Major taxa are ranked in each dosage block. Preceding each major taxon or genus is the relative percentage that organism represents, also pooled for eight test units.

It is immediately obvious that amphipods are typically the dominant organisms in these communities. Presently amphipods are being sorted to species since there is seasonality of occurrence among the species involved. Principally, three forms dominate (courtesy Dr. E. L. Bousfield, National Museum of Canada): Gammarus macronatus, Coropbium acherusicum, and Merita nitida along with two Caprellidae.

There are a number of simultaneous patterns apparent from these preliminary data. (1) Generally low variation exists between pairs of dosage levels at a given month (harvest), (2) Significant variance, when occurring, is most often between Lo (control) and L 3 (highest dose). (3) Diversity of forms (by major taxon accounting) is lowest in late summer, autumn and winter months (1975) as compared to spring.

None of these generalized results is surprising in itself, but the consistency among similar test containers has been gratifying and reassuring. Additional analyses incorporating species level identification, accounting for sedimentation rates, and perhaps most importantly, the patterns of macroalgae are underway at this time and promise to reveal additional factoral interactions for chlorination. Qualitatively, we observe that there is a strong seasonal/dosage response by a form of a chain diatom (Melosira) and other algae (Ulva, Enteromorpha, and examples of Cladophorales).

Yet to be understood is the potential interaction of specific marine water chlorination by-products such as bromate (Macalady et al., in press) or bromoform especially formed by sunlight photolysis.

Preliminary investigations performed by Erickson \& Foulk (in press) on effects of chlorination upon the natural levels of adenosine triphosphate (ATP) reveals a high correlation of reduced ATP levels with increased chlorination rates. This agrees with field measurements reported previously (Gentile et al., 1976).

In conclusion from the first year operation the METU design has yielded multidimensional physical, chemical, and biological data indicating that there is a "holistic" ecosystem response to chlorination by marine benthic organisms in South Carolina estuarine waters. Since these organisms are responding variably over the seasons, and the chlorination is chemically subdetectable in all but the coldest conditions $\left(5^{\circ} \mathrm{C}\right)$ we continue our analyses to more clearly elucidate these preliminary results. 
Acknowledgements. This experiment is completely dependent upon the combined efforts of a number of persons. The attentions of Stan Erickson and Howard Foulk guaranteed the development of the design concept into a functional testing system. The unsung heroes are the people, self proclaimed "pickers", who sort and enumerate the hundreds of thousands of marine organisms comprising the analytical data base. Miss Grace Kennedy prepared the illustrations. The authors wish to thank many people who contributed to these combined efforts, including those wise observers who noted only the foolhardy would undertake such an effort. - This paper is contribution No. 321 of Gulf Breeze Environmental Research Laboratory.

\section{LITERATURE CITED}

Carpenter, J. H. \& Macalady, D. L., 1976. Chemistry of halogens in seawater. In: Proceedings of conference: The environmental impact of water chlorination. Ed. by R. L. Jolley. Oak Ridge National Laboratory Conf. 751096, 177-193.

Davis, W. P. \& Middaugh, D. P., 1976. A review of the impact of chlorination. Processes upon marine ecosystems. In: Proceedings of conference: The environmental impact of water chlorination. Ed. by R. L. Jolley. Oak Ridge National Laboratory Conf. 751096, 299-325.

Dove, R. A. 1970. Reaction of small dosages of chlorine in seawater. Central Electricity Generating Board. Central Electric Research Laboratories, Surrey (Service Research Rep. 42/70, Microfiche).

Gentile, J. H., Cardin, J., Johnson, M. \& Sosnowski, L., 1976. Power plants, chlorine, estuaries. U.S. Environmental Protection Agency, Office of Research and Development Publication, Washington, $28 \mathrm{pp}$. (Ecological Research Series EPA 600/3-76-055).

Jolley, R. L. (Ed.), 1976. The environmental impact of water chlorination. Proceedings of conference: Oak Ridge National Laboratory Conf. 751096, UC-11, 1-443.

Livingston, R. J. (Ed.), 1974. Synergistic bioassays. In: Proceedings of a workshop on marine bioassays. Marine Technology Society, Washington, D.C., 308 pp.

Macalady, D. L., Carpenter, J. H. \& Moore, C. H., 1977. Sunlight-induced bromate formation in chlorinated seawater. Science, N.Y. 195, 1335-1337.

Smith, W. \& Grassle, J. F., 1977. Sampling properties of a family of diversity measures. Biometrics (in press).

Author's address: Dr. W. P. Davis

U.S. Environmental Protection Agency

Bears Bluff Field Station

P.O.B. 368

Johns Island, South Carolina 29455

USA 